ONLINE MUTATION REPORT

\title{
Mowat-Wilson syndrome and mutation in the zinc finger homeo box 1B gene: a well defined clinical entity
}

\author{
P Cerruti Mainardi, G Pastore, C Zweier, A Rauch
}

J Med Genet 2004;41:e16 (http://www.jmedgenet.com/cgi/content/full/41/2/e16). doi: 10.1136/jmg.2003.009548

M owat et al in 1998 delineated a new syndrome characterised by a distinct facial phenotype, Hirschsprung disease (HSCR), microcephaly, and mental retardation; they also identified a locus at chromosome 2q21-q23. ${ }^{1}$ The six children described were sporadic cases, and the authors suggested a contiguous gene syndrome or a dominant single gene disorder. Three further sporadic cases published earlier as having unclassified syndromic HSCR, Goldberg-Shprintzen syndrome, or 2q2223 deletion, ${ }^{2-4}$ were recognised by Mowat et al having the same distinctive facial appearance as their patients. Kääriäinen et al reported five patients with a similar phenotype. ${ }^{5}$ Mutations in ZFHXIB (SIPI) were identified by Wakamatsu et al in a patient with a translocation $\mathrm{t}(2 ; 13)(\mathrm{q} 22 ; \mathrm{q} 22)$ and in another three patients, all with syndromic HSCR. ${ }^{6}$ Mutations in ZFHXIB (SIPl) were also identified by Cacheux et $a l^{7}$ in two patients of Kääriäinen et $a l^{5}$ : patient 1 with a $\mathrm{t}(2 ; 11)(\mathrm{q} 22.2 ; \mathrm{q} 21)$ and in patient 3; and in patients 1,2, and 3 of Mowat et al. ${ }^{1}$ Subsequently Yamada et al reported $Z F H X I B$ mutations in other patients with complex developmental disorders, ${ }^{8}$ as did Amiel et al in patients with syndromic Hirschsprung disease. ${ }^{9}$ Investigation of four patients by Zweier $e t a l^{10}$ and one patient by Garavelli et $a l^{11}$ showed the distinct phenotype and the mutation in $Z F H X I B(S I P I)$ and confirmed the syndrome described by Mowat et al. ${ }^{1}$ Recently an article by Wilson et al reported 15 new patients with ZFHXIB mutations, and a review of Mowat-Wilson syndrome was published by Mowat et al. ${ }^{12} 13$

Although in total 45 cases with deletions or mutations in ZFHXIB (SIPI) have been recorded, ${ }^{4-14}$ detailed clinical descriptions are rare. We report two new patients from Northern Italy with all the typical signs of the syndrome and with mutations in ZFHXIB (SIPI).

\section{CLINICAL DESCRIPTION}

\section{Patient 1}

This boy was the first child of unrelated parents. The sister was healthy. He was born at 41 weeks' gestation with a birth weight of $3200 \mathrm{~g}$ (10th-25th centile), a length of $48 \mathrm{~cm}$ (10th), and a head circumference of $33 \mathrm{~cm} \mathrm{(3rd-10th).}$ Hirschsprung disease (HSCR) was diagnosed on day 2; a colostomy was carried out on day 3 and closed at 8 months. He had serious constipation from the first months of life and also a high degree of vescicoureteric reflux. At 14 months, hypotonia and psychomotor developmental delay was observed. Because of facial abnormalities a karyotype was performed, with normal results. He developed seizures at 16 months, when EEG showed epileptic anomalies prevailing on the right hemisphere, and sodium valproate therapy was started.

On examination at 5 years of age, the boy showed several minor facial anomalies: fine hair, high forehead, frontal bossing, broad nasal bridge, medially flaring thick eyebrows,

\section{Key points}

- In 1998 a new syndrome characterised by a distinct facial phenotype, Hirschprung disease (HSCR), microcephaly, and mental retardation was delineated by Mowat et al, who also identified a locus at chromosome 2q21-q23. In 2001, mutations in ZFHX1B were reported by Wakamatsu et al in patients with syndromic HSCR, and by Cacheux et al in patients of Mowat et al. Zweier et al pointed out that "MowatWilson" syndrome was a distinct and recognisable syndrome, caused by mutations in the ZFHXIB gene, in which the presence of HSCR was not constant.

- We observed two new patients with all typical signs of Mowat-Wilson syndrome, which enabled us to confirm that it is typical and recognisable, like classical genetic syndromes, and finds its marker in ZFHXIB (SIPI) gene mutation. The comparison with the other 45 patients with deletions or mutations in ZFHXIB (SIPI) as reported up to now shows a striking resemblance of the facial features, and uniformity of the associated malformations as well as of clinical problems and severe mental retardation.

- We wish to highlight the importance of clinical recognition of the syndrome with or without HSCR in the selection of patients for cytogenetic and molecular analyses. An early diagnosis is also important for genetic counselling, to distinguish this syndrome from others with HSCR and autosomal recessive transmission, since patients with Mowat-Wilson syndrome so far reported have been sporadic cases.

- Our two patients with the same severe phenotype as the patients reported with large q22 deletions show that Mowat-Wilson syndrome is not a contiguous gene syndrome, and that truncating mutations of one allele of the ZFHXIB gene involved in neural crest development result in this complex phenotype.

- The new heterozygous stop mutation Y293X in patient 2 is novel. Patient 1 shows a heterozygous stop mutation R695X, already reported in other 5 patients. Comparison of the clinical data of these six patients concerning the associated malformations demonstrates the phenotypic variability of a single mutation in Mowat-Wilson syndrome.

Abbreviations: HSCR, Hirschsprung disease 

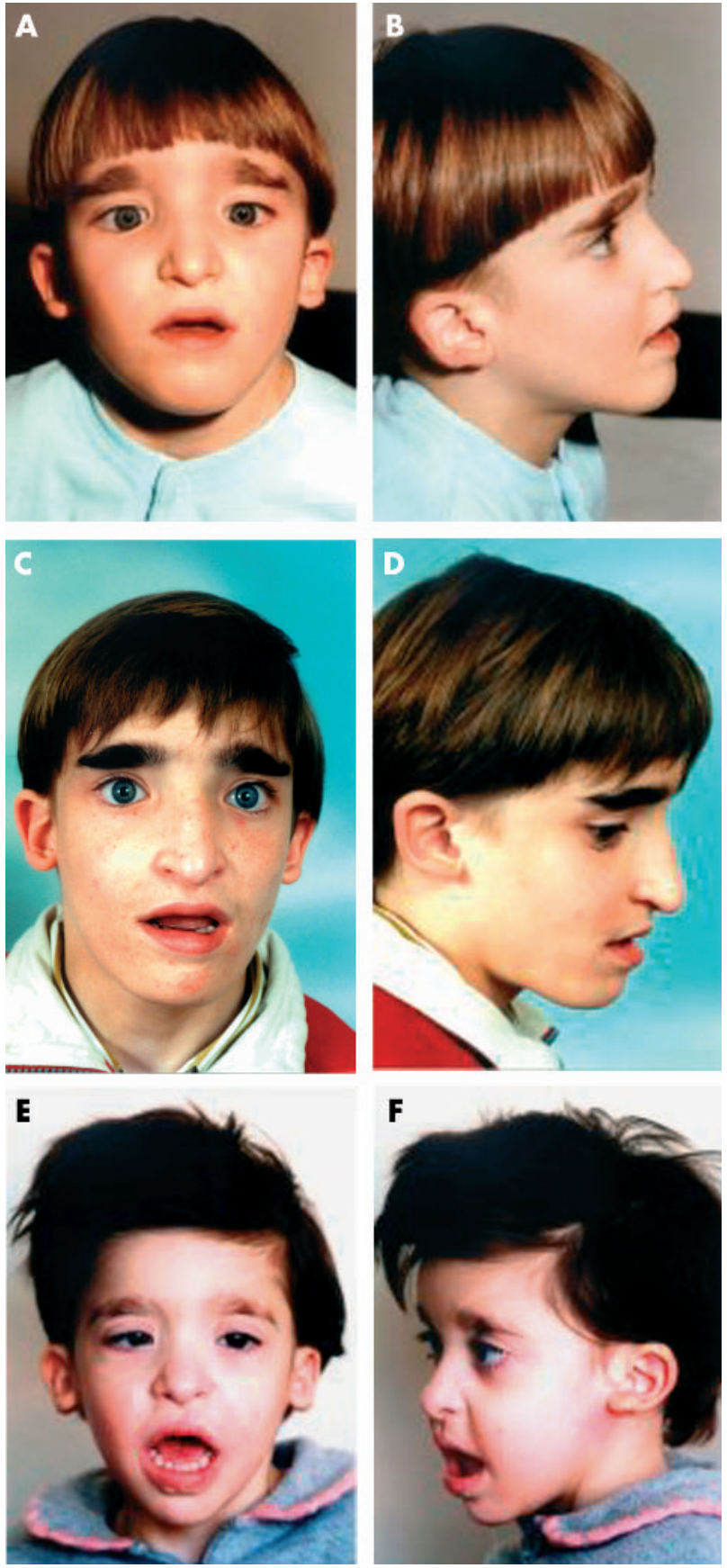

Figure 1 (A) and (B), patient 1 at age 5 years. (C) and (D), patient 1 at age 13 years and 8 months. $(E)$ and $(F)$, patient 2 at age 3 years and 5 months.

downward slanting palpebral fissures, hypertelorism, epicanthus, deepset blue eyes, small nose with prominent columella, open mouth, triangular jaw, prominent chin, and posterior lowset ears with uplifted lobes, shown in fig $\mathrm{l}(\mathrm{A})$ and (B). He also presented a high arched palate, penoscrotal hypospadias with penis recurvation (treated surgically at 4 years 5 months), right cryptorchidism, pes planus with calcaneovalgus, mild pectus excavatum, long tapered fingers, single transverse palmar creases, microcephaly $(48.5 \mathrm{~cm},<3 \mathrm{rd}$ centile), and severe psychomotor retardation. Denver testing ${ }^{15}$ showed that he grasped at 15 months; he walked alone at 3 years; and he was affectionate and smiling, but had no speech. A cardiac systolic murmur was present. ECG was normal, but echocardiography showed a mild fibrosis of the anterior leaflet of the tricuspid valve with slight valvular insufficiency. Seizures were frequent and resistant to treatment. MRI of the brain showed a marked hypoplasia of the corpus callosum and narrow cerebral ventriculi. Audiometric examination was normal; ocular fundus examination showed in the right eye an optic papilla with a grey pigmentary halo, whereas the left eye was normal. Standard karyotyping was repeatedly normal, and FRAXA mutation, Angelman syndrome, and metabolic diseases were excluded.

On the last examination at 13 years and 8 months, patient I's weight was $29 \mathrm{~kg}$ (<3rd centile), his height was $138 \mathrm{~cm}$ $(<3 \mathrm{rd})$ (target $>10$ th), and his head circumference was $50 \mathrm{~cm}(<3 \mathrm{rd})$. A long face, horizontal palpebral fissures, less evident epicanthic folds, and abnormal maxillary incisors were observed. The other facial anomalies were unchanged, as shown in fig 1 (C) and (D). Thinness was present; pubertal development was advanced. No seizures had occurred from age 8 years; EEG showed non-specific anomalies. The severe psychomotor and mental retardation persisted. Denver testing ${ }^{15}$ revealed that the patient ran and walked up steps at 6 years; drank unaided at 8 years; was toilet trained with help at 8 years; and still had no speech.

Since we suspected that he had Mowat-Wilson syndrome, ZFHXIB mutational analysis was performed.

\section{Patient 2}

This girl was the first child of unrelated parents. The brother was healthy. She was born at 41 weeks' gestation with a birth weight of $3700 \mathrm{~g}$ (75th centile), a length of $51 \mathrm{~cm}$ (75th), and a head circumference of $32 \mathrm{~cm}$ (3rd). Cyanosis and cardiac systolic murmur were present at birth, and echocardiogram showed Fallot's tetralogy with an absent pulmonary valve. Dysmorphism was observed but the karyotype was normal. At 20 days the patient had vomiting and abdominal distension; HSCR was diagnosed, and a colostomy was carried out at day 22. When, at 3 months, surgery for the Fallot's tetralogy was performed, agenesis of the pulmonary valve and severe dilation of pulmonary branches were found. At 11 months the colostomy was closed. At 1 year of age the patient developed recurrent seizures; EEG showed slow widespread anomalies prevalent on frontotemporal bilateral derivations, and phenobarbitone therapy was started. Ultrasound of the brain recorded hypoplasia of the corpus callosum. During the first year of life hypotonia and psychomotor retardation were observed.

On the last examination at 3 years and 5.5 months, the patient's weight was $11.3 \mathrm{~kg}$ (<3rd centile), length $93 \mathrm{~cm}$ (25th), and head circumference $43 \mathrm{~cm}(<3 \mathrm{rd})$. She had fine hair, a high forehead, frontal bossing, prominent supraorbital ridges, medially flaring eyebrows, hypertelorism, deepset eyes, a small nose with a prominent columella, open mouth, prominent chin, and posterior lowset ears with uplifted lobes, shown in fig $\mathrm{l}(\mathrm{E})$ and $(\mathrm{F})$. She also presented a high arched palate, long tapered fingers, single incomplete transverse palmar creases, and pes planus with calcaneovalgus. A cardiac systolic murmur persisted and seizures were recurrent. Cranial MRI confirmed hypoplasia of the corpus callosum. She presented a severe psychomotor retardation; Denver testing ${ }^{15}$ revealed that she sat "head steady" at 1 year, did not sit without support, grasped at 2.5 years, and turned to voice at 2 years and had no speech.

As the clinical picture was typical of Mowat-Wilson syndrome, ZFHXIB mutational analysis was undertaken.

\section{METHODS AND RESULTS ZFHX $1 B$ investigations}

FISH analysis for exclusion of whole gene deletions was performed as described earlier, ${ }^{10}$ with normal results in both 


\section{ZFHXIB}

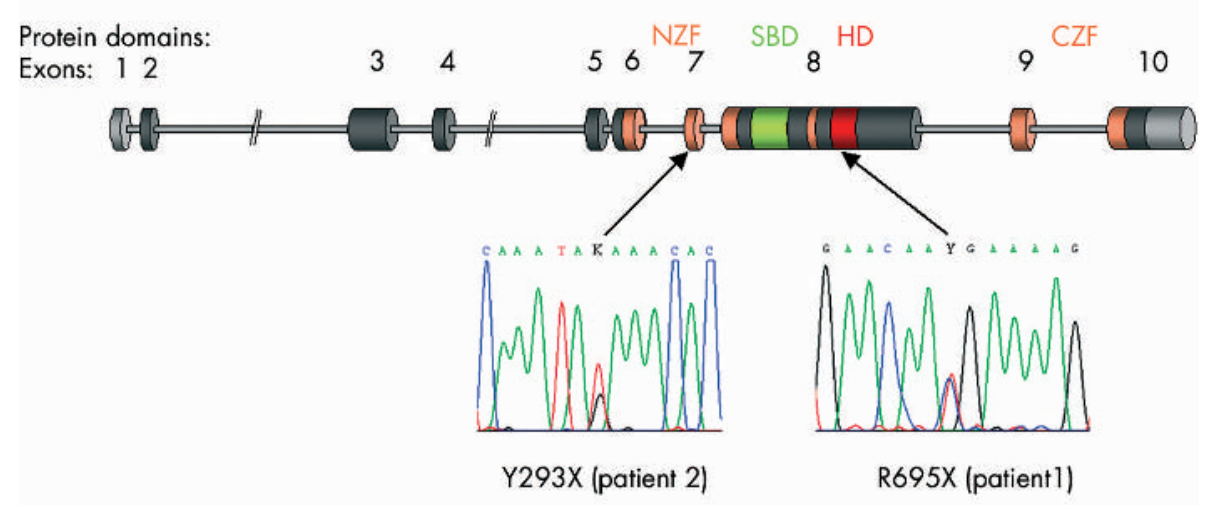

Figure 2 Scheme of ZFHXIB exons and corresponding protein structure adapted from Zweier et al, ${ }^{10}$ showing the position of the presented mutations. $\mathrm{NZF}, \mathrm{N}$-terminal zinc finger cluster; $\mathrm{CZF}, \mathrm{C}$-terminal zinc finger cluster; $\mathrm{SBD}$, Smad binding domain; HD, homeodomain-like segment. patients. Sequencing of the complete coding sequence of ZFHXIB ${ }^{10}$ showed a new heterozygous exon 8 stop mutation nt2083 c-t (R695X) in patient 1 , and a new heterozygous exon 7 stop mutation nt $879 \mathrm{t}$-g (Y293X) in patient 2 (fig 2).

In tables 1 and 2, clinical and molecular data on our two patients are compared with those of the 45 patients with deletion or mutation in ZFHXIB (SIPI) so far reported. ${ }^{14-14}$

\section{DISCUSSION}

These patients presented all the clinical features of MowatWilson syndrome, as defined by Zweier et $a l^{10}$ and Garavelli et $a l,{ }^{11}$ and confirm that it is distinct and recognisable like classical genetic syndrome that finds its marker in $Z F H X I B$
(SIPI) gene mutations. The clinical picture is different from that of Goldberg-Shprintzen syndrome, ${ }^{16}$ which is characterised by a different facial phenotype; commonly palpebral ptosis and cleft palate are commonly observed as well as generally milder mental retardation. Only two of at least 17 published cases supposed to have Goldberg-Shprintzen syndrome occurred sporadically, the majority of cases being sibs and/or offspring of consanguineous mating. ${ }^{216-23}$ Only recently a patient with suggested Goldberg-Shprintzen syndrome was investigated for ZFHXIB mutations and was shown to have none. ${ }^{24}$ The differential diagnosis is important for genetic counselling, because Goldberg-Shprintzen syndrome is most likely autosomally recessive, whereas all

\begin{tabular}{|c|c|c|c|c|}
\hline Clinical features & 1 & 2 & Total patients(S) & $\%$ of total \\
\hline \multicolumn{5}{|l|}{ Facial characteristics } \\
\hline Sparse/fine hair & + & + & $9 / 13(N)$ & 69.2 \\
\hline High, broad forehead/frontal bossing & + & + & $9 / 11$ & 81.8 \\
\hline Medially flaring thick eyebrows & + & + & $36 / 36$ & 100.0 \\
\hline Hypertelorism & + & + & $38 / 38$ & 100.0 \\
\hline Strabismus & - & + & $18 / 23$ & 78.3 \\
\hline Deepset eyes & + & + & $36 / 36$ & 100.0 \\
\hline Epicanthus & + & - & $8 / 13$ & 61.5 \\
\hline Downward slanting palpebral fissures & + & + & $11 / 15$ & 73.3 \\
\hline Broad nasal bridge/saddle nose & + & + & $42 / 43$ & 97.7 \\
\hline Small nose, round tip/prominent columella & + & + & $28 / 29$ & 96.5 \\
\hline Open mouth & + & + & $24 / 28$ & 85.7 \\
\hline Prominent pointed chin/triangular jaw & + & + & $40 / 40$ & 100.0 \\
\hline $\begin{array}{l}\text { Posterior lowset ears with uplifted lobes } \\
\text { Other malformations and problems }\end{array}$ & + & + & $36 / 36$ & 100.0 \\
\hline $\begin{array}{l}\text { Other malformations and problems } \\
\text { HSCR }\end{array}$ & + & + & $30 / 47$ & 63.8 \\
\hline Seizures & + & + & $35 / 46$ & 76.1 \\
\hline Congenital heart disease & - & + & $22 / 47$ & 46.8 \\
\hline Agenesis/hypoplasia of corpus callosum & + & + & $15 / 33$ & 45.4 \\
\hline Renal anomalies & + & - & $10 / 27$ & 37.0 \\
\hline Hypospadias & + & $15 \mathrm{NR}$ & $12 / 25$ & 48.0 \\
\hline Cryptorchidism & + & $15 \mathrm{NR}$ & $11 / 25$ & 44.0 \\
\hline Cleft submucous palate / high arched palate & + & + & $10 / 27$ & 37.0 \\
\hline Dermatoglyphic anomalies & + & + & $8 / 9$ & 88.8 \\
\hline Tapered fingers & + & + & $16 / 19$ & 84.2 \\
\hline Pes planus with calcaneovalgus & + & + & $10 / 11$ & 90.9 \\
\hline Mental retardation & + & + & $47 / 47$ & 100.0 \\
\hline Microcephaly ( $\leqslant 3$ rd centile at last follow up) & + & + & $40 / 46$ & 86.9 \\
\hline Hypotonia & + & + & $25 / 26$ & 96.2 \\
\hline Short stature ( $<3$ rd centile at last follow up) & + & - & $12 / 29$ & 41.4 \\
\hline Happy, affectionate personality & + & + & $24 / 25$ & 96.0 \\
\hline
\end{tabular}


รั)

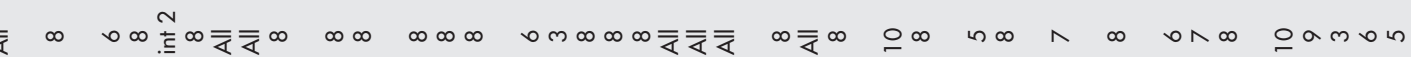

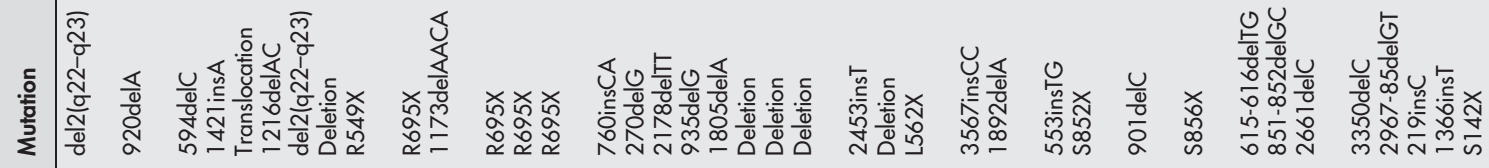
芒

3

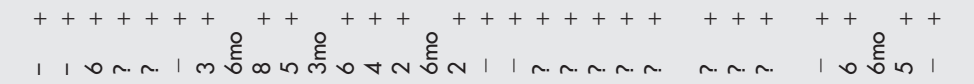

旁

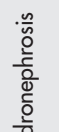

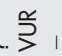
京.

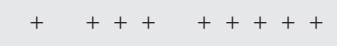

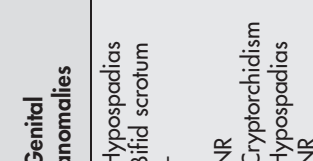

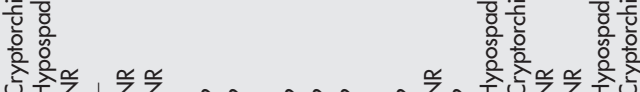
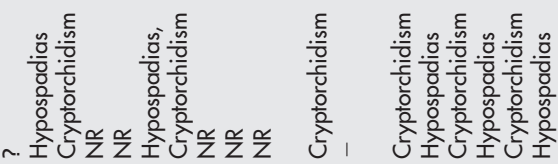

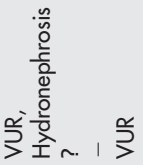
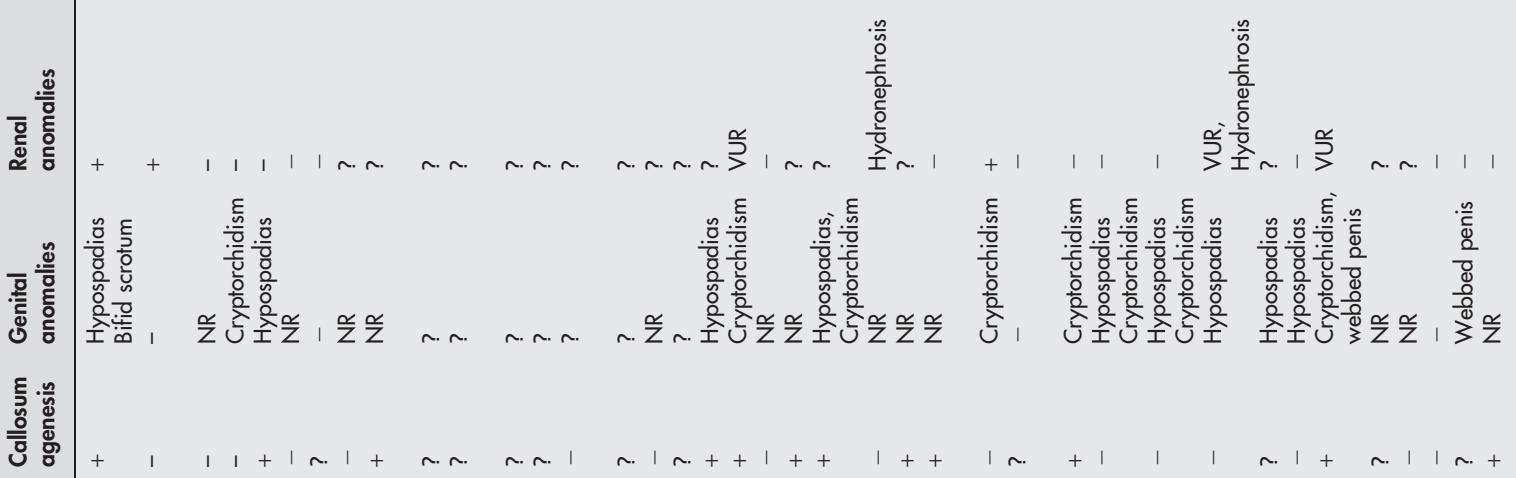

声若

产

흔

옳

语密画

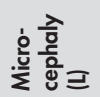

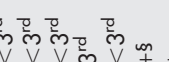

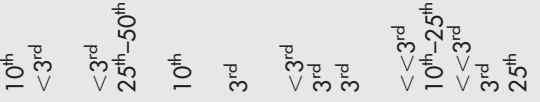

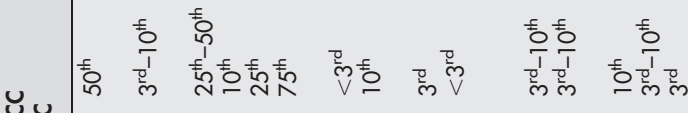

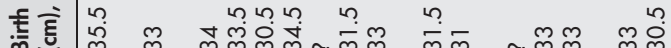

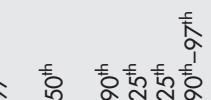

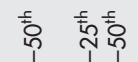

走啇

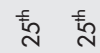

衰套

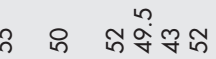

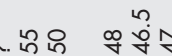

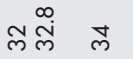

$=$

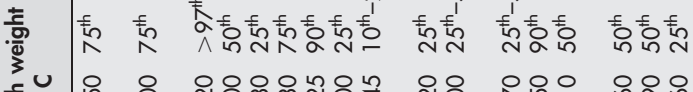

형해 형혀 햇

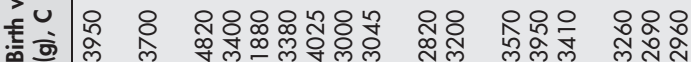

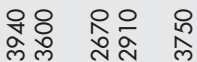

.흘

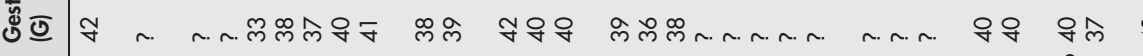

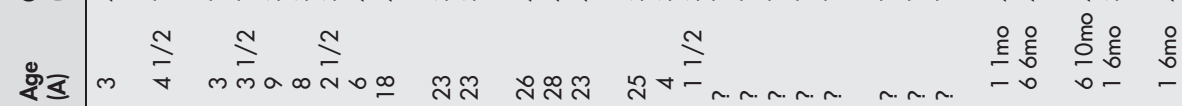

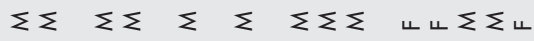

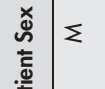

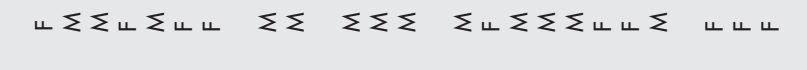

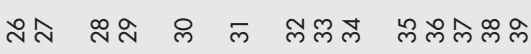

全

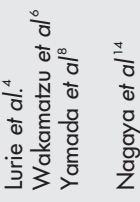

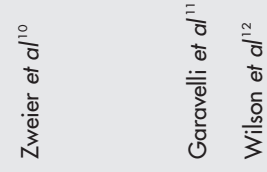




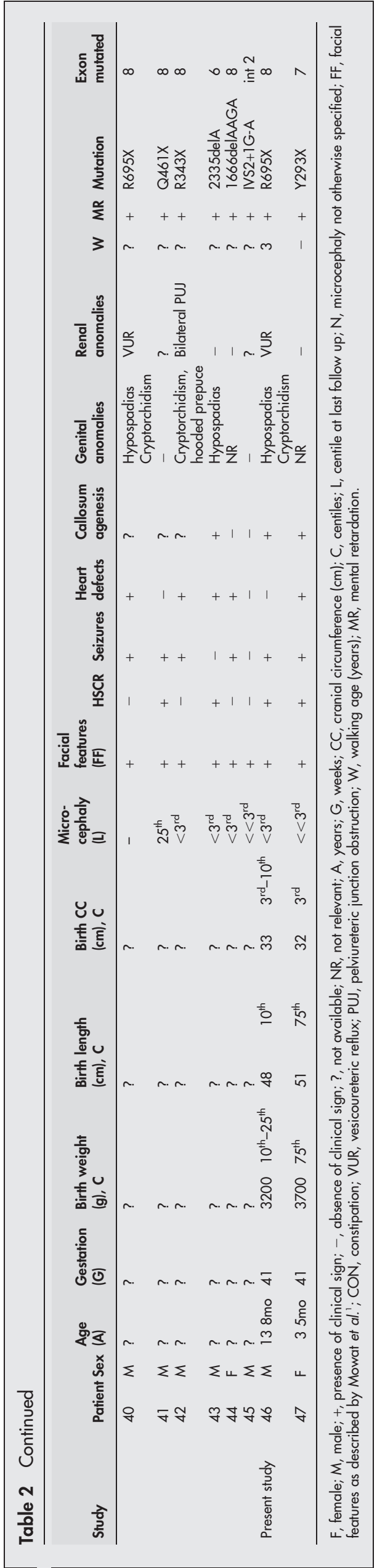

patients with Mowat-Wilson syndrome so far reported have been sporadic cases.

Mowat-Wilson syndrome patients, besides having a distinct facial phenotype and severe mental retardation, often present HSCR, epilepsy, and major and minor malformations which suggest the diagnosis and direct analyses to a rearrangement in 2q22-q23 or, if not present, in the gene mutation. The presence of HSCR is a strong cross reference marker, and the importance of a careful clinical assessment in all newborns with HSCR has been outlined recently. ${ }^{25}$ On the other hand, Zweier et $a l^{10}$ found the ZFHXIB mutation in all four patients with typical facial phenotype, two having and two not having HSCR. The mutation was not found in the fifth patient with syndromic HSCR but different facial anomalies. The authors conclude that HSCR is one of the multiple variable anomalies of Mowat-Wilson syndrome.

Wakamatsu et $a l^{6}$ identified a ZFHXIB deletion in a patient with translocation $\mathrm{t}(2 ; 13)(\mathrm{q} 22 ; \mathrm{q} 22)$, and $Z F H X 1 B$ mutations in another three patients with syndromic HSCR selected from a series of 200 patients with HSCR. The same authors ${ }^{8}{ }^{14}$ in a study of 10 patients with mutation in ZFHXIB (including the four patients previously described $)^{6}$ found HSCR only in four out of 10 (two did not have HSCR, four had constipation), and they concluded that the mutation in ZFHXIB caused a complex developmental disorder with a great variety of clinical features. They ${ }^{14}$ also noticed a strong resemblance of these patients to those described by Mowat et al. ${ }^{1}$ Amiel et al, ${ }^{9}$ in a study of the ZFHXIB mutation in 19 patients with syndromic HSCR selected from 250 patients with HSCR, showed a mutation in eight patients (one of them with constipation only). They emphasised the fact that Mowat et $a l^{1}$ first recognised the distinct clinical features of these patients and identified a locus at chromosome 2q22-23. Recently Wilson et $a l^{12}$ and Mowat et al ${ }^{13}$ reported 15 new patients with ZFHXIB mutations and provided a detailed discussion on the clinical features and the change in facial phenotype with age in this syndrome.

The comparison of the data on our patients with those on the 45 patients with mutation in ZFHXIB already reported in the literature (tables 1 and 2), showed that the main facial features (medially flaring thick eyebrows, hypertelorism deepset eyes, strabismus, broad nasal bridge, rounded nasal tip, open mouth, prominent pointed chin, and lowset ears with uplifted lobes) described by Mowat et al ${ }^{13}$ were present in most of the patients (table 1). These observations, together

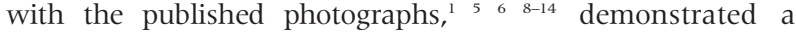
striking resemblance in facial features. Furthermore, in these patients there was a high frequency of some major malformations, such as HSCR (63.8\%), heart defects $(46.8 \%)$, agenesis of the corpus callosum $(45.4 \%)$, and seizures $(76.1 \%$ ) (table 1 ). Minor malformations were frequent but not invariably reported. The mental retardation, usually severe, was constant; the delay in the acquisition of motor skills was more variable (table 2). The male/female ratio was 2.13/1, the difference being statistically significant $(\mathrm{p}<0.01)$ compared with the general population. The patients presented normal weight and length at birth. The cranial circumference at birth was close to or below the 3rd centile in 11 out of 19 patients $(58 \%)$ (and in general one centile less than that of weight and height), whereas 40 out of 46 patients (86.9\%) had a cranial circumference on or below the 3rd centile at the last follow up (tables 1 and 2). On the grounds of these observations we want to highlight the importance of clinical recognition of the syndrome with or without HSCR, in order to select cases for cytogenetic and molecular analyses.

Whereas our patient l's mutation R695X had already been reported in a patient with syndromic HSCR, ${ }^{6}$ in three patients 
with complex developmental disorder, ${ }^{8}$ and in one patient of Wilson et al, ${ }^{12}$ the mutation Y293X in our patient 2 was novel. The latter would result in a premature translational stop within the N-terminal zinc finger cluster of the putative protein, which therefore would miss the Smad binding domain, the homeodomain, and the C-terminal zinc finger cluster. Our patient with the R695X mutation had HSCR, as did one of the reported cases, but of the remaining four patients one did not have HSCR and three had moderate to severe constipation only. Congenital heart defects were reported in one of them. Agenesis of corpus callosum was seen in our patient, and excluded in the only reported patient who had had brain studies. Thus, some phenotypic variability of a single mutation is demonstrated in Mowat-Wilson syndrome. Genotype-phenotype correlation in large scale deletions have been discussed elsewhere. ${ }^{26}$

These two patients, with the same severe phenotype as the patients reported with large q22 deletions, show that MowatWilson syndrome is not a contiguous gene syndrome, and that truncating mutations of one allele of the ZFHXIB gene involving neural crest development result in this complex phenotype. Nevertheless, it is noteworthy that an atypical phenotype with late adult onset severe constipation and mild mental retardation in the absence of specific facial anomalies, seizures, and other malformations might be caused by nontruncating mutations, such as a 3 bp in frame deletion. ${ }^{27}$

A Mowat-Wilson syndrome mutation database will be available at following URL: http://www.humgenet.uni-erlangen. de/2kforschung mowat-syndrom.html

\section{ACKNOWLEDGEMENTS}

We wish to thank M Godi, research assistant, and the Fondazione Cassa di Risparmio di Vercelli for its support. We are grateful to the families for their cooperation.

\section{Authors' affiliations \\ P Cerruti Mainardi, G Pastore, Pediatric Department and Genetics Unit, S. Andrea Hospital, Vercelli, Italy \\ C Zweier, A Rauch, Institute of Human Genetics, Friedrich Alexander University of Erlangen-Nuremberg, Erlangen, Germany}

A Mowat-Wilson syndrome mutation database will be available at following URL: http://www.humgenet.uni-erlangen.de/2kforschung mowat-syndrom.html

Correspondence to: Dr P Cerruti Mainardi, Divisione di Pediatria Servizio di Genetica, Ospedale S. Andrea, Corso Abbiate 21, 13100 Vercelli, Italy; pcerruti@net4u.it

Received 11 April 2003

Accepted 3 June 2003

\section{REFERENCES}

1 Mowat DR, Croaker GDH, Cass DT, et al. Hirschsprung disease, microcephaly, mental retardation, and characteristic facial features: delineation of a new syndrome and identification of a locus at chromosome 2q22-q23. J Med Genet 1998;35:617-23.

2 Hurst JA, Markiewicz M, Kumar D, et al. Unknown syndrome: Hirschsprung's disease, microcephaly, and iris coloboma: a new syndrome of defective neuronal migration. J Med Genet 1988;25:494-7.
3 Tanaka H, Ito J, Cho K, et al. Hirschsprung disease, unusual face, mental retardation, epilepsy, and congenital heart disease: Goldberg-Shprintzen syndrome. Pediatr Neurol 1993;9:479-81.

4 Lurie IW, Supowitz KR, Rosenblum-Vos LS, et al. Phenotypic variability of del(2)(q22-q23): report of a case and review of the literature. Genet Couns 1994;5:11-14

5 Kääriäinen $\mathrm{H}$, Wallgren-Pettersson C, Clarke A, et al. Hirschsprung disease, mental retardation and dysmorphic facial features in five unrelated children. Clin Dysmorphol 2001;10:157-63.

6 Wakamatsu N, Yamada Y, Yamada K, et al. Mutations in SIP1, encoding Smad interacting protein-1, cause a form of Hirschsprung disease. Nat Genet $2001 ; 27: 369-70$.

7 Cacheux V, Dastot Le Moal F, Kääriäinen H, et al. Loss - of - function mutations in SIPI Smad interacting protein 1 result in a syndromic Hirschsprung disease. Hum Mol Genet 2001;10:1503-10.

8 Yamada K, Yamada Y, Nomura N, et al. Nonsense and frameshift mutations in $Z F H X 1 B$, encoding Smad-interacting protein 1, cause a complex developmental disorder with a great variety of clinical features. Am J Hum Genet 2001;69:1178-85.

9 Amiel J, Espinosa-Parrilla Y, Steffann J, et al. Large-scale deletions and SMADIP1 truncating mutations in syndromic Hirschsprung disease with involvement of midline structures. Am J Hum Genet 2001;69:1370-7.

10 Zweier C, Albrecht B, Mitulla B, et al. "Mowat-Wilson" syndrome with and without Hirschsprung disease is a distinct, recognizable multiple congenital anomalies-mental retardation syndrome caused by mutations in the Zinc Finger Homeo Box 1 B gene. Am J Med Genet 2002;108:177-81.

11 Garavelli L, Donadio A, Zanacca C, et al. Hirschsprung disease, mental retardation, characteristic facial features, and mutation in the gene ZFHXIB (SIPI): confirmation of the Mowat-Wilson syndrome. Am J Med Genet 2003;116A:385-8.

12 Wilson M, Mowat D, Dastot-LeMoal F, et al. Further delineation of the phenotype associated with heterozygous mutations in ZFHX1B. Am J Med Genet 2003;119(A):257-65.

13 Mowat DR, Wilson MJ, Goossens M. Mowat-Wilson syndrome. J Med Genet 2003;40:305-10.

14 Nagaya M, Kato J, Niimi N, et al. Clinical features of a form of Hirschsprung's disease caused by a novel genetic abnormality. J Pediatr Surg 2002;37:1117-22.

15 Frankenburg WK, Dodds JB, Archer P, et al. The Denver II: a major revision restandardization of the Denver Developmental Screening Test. Pediatrics 1992;89:91-7

16 Goldberg RB, Shprintzen RJ. Hirschsprung megacolon and cleft palate in two sibs. J Craniofac Genet Dev Biol 1981;1:185-9.

17 Brunoni D, Joffe R, Farah LM, et al. Syndrome identification case report 92: Hirschsprung megacolon, cleft lip and palate, mental retardation, and minor congenital malformations. J Clin Dysmorphol 1983;1:20-2.

18 Kumasaka K, Clarren SK. Familial patterns of central nervous system dysfunction, growth deficiency, facial clefts and congenital megacolon: a specific disorder? Am J Med Genet 1988;31:465-6.

19 Breslau L, Laan L. Facial cleft and congenital megacolon: a specific disorder? Am J Med Genet 1989;34:613.

20 Halal F, Morel J. The syndrome of Hirschsprung disease, microcephaly, unusual face, and mental retardation. Am J Med Genet 1990;37:106-8

21 Yomo A, Taira T, Kondo I. Goldberg-Shprintzen syndrome: Hirschsprung disease, hypotonia, and ptosis in sibs. Am J Med Genet 1991;41:188-91.

22 Fryer AE. Goldberg-Shprintzen syndrome: report of a new family and review of the literature. Clin Dysmorphol 1998;7:97-101.

23 Brooks AS, Breuning MH, Osinga B, et al. A consanguineous family with Hirschsprung disease, microcephaly, and mental retardation (GoldbergShprintzen syndrome). J Med Genet 1999;36:485-9.

24 Silengo $M$, Ferrero GB, Tornetta L, et al. Pachygyria and cerebellar hypoplasia in Goldberg-Shprintzen syndrome. Am J Med Genet 2003;118(A):388-90.

25 Amiel J, Lyonnet S. Hirschsprung disease, associated syndromes, and genetics: a review. J Med Genet 2001;38:729-39.

26 Zweier C, Temple IK, Beemer F, et al. Characterization of deletions of the ZFHX1B region and genotype-phenotype analysis in Mowat-Wilson syndrome. J Med Genet 2003;40:601-5.

27 Yoneda M, Fujita T, Yamada Y, et al. Late infantile Hirschsprung diseasemental retardation syndrome with a 3-bp deletion in ZFHX1B. Neurology 2002; 59: 1637-40. 